\title{
Correction to: Metabotropic group II glutamate receptors in the basolateral amygdala mediate cue-triggered increases in incentive motivation
}

\section{Caroline Garceau $^{1} \cdot$ Anne-Noël Samaha ${ }^{1,2} \cdot$ Thomas Cordahi $^{3} \cdot$ Alice Servonnet $^{3} \cdot$ Shaun Yon-Seng Khoo ${ }^{1}$}

Published online: 6 September 2021

๑) Springer-Verlag GmbH Germany, part of Springer Nature 2021

\section{Correction to: Psychopharmacology.}

https://doi.org/10.1007/s00213-021-05907-7

In the published article, the figures were incorrectly presented without panel titles. The corrected figures with panel titles included are presented below.

The original article has been corrected.

Supplementary Information The online version contains supplementary material available at https://doi.org/10.1007/s00213-021-05959-9.

Publisher's note Springer Nature remains neutral with regard to jurisdictional claims in published maps and institutional affiliations.

The original article can be found online at https://doi.org/10.1007/ s00213-021-05907-7.

Caroline Garceau and Anne-Noël Samaha contributed equally to this work.

Anne-Noël Samaha

anna.samaha@umontreal.ca

1 Department of Pharmacology and Physiology, Faculty of Medicine, Universite de Montreal, Montreal, QC H3T 1J4, Canada

2 CNS Research Group, Faculty of Medicine, Universite de Montreal, Montreal, QC H3T 1J4, Canada

3 Department of Neurosciences, Faculty of Medicine, Universite de Montreal, Montreal, QC H3T 1J4, Canada 


\section{a. Timeline and Behavioural Schematic}

Instrumental Training

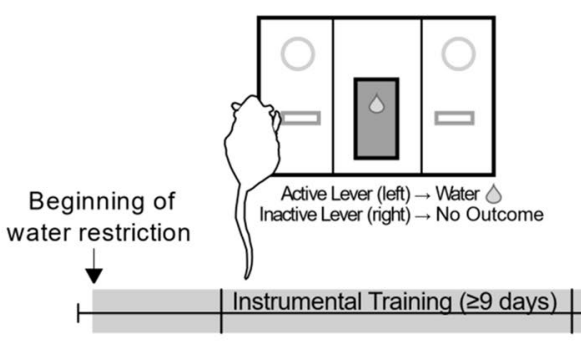

b. Instrumental Training

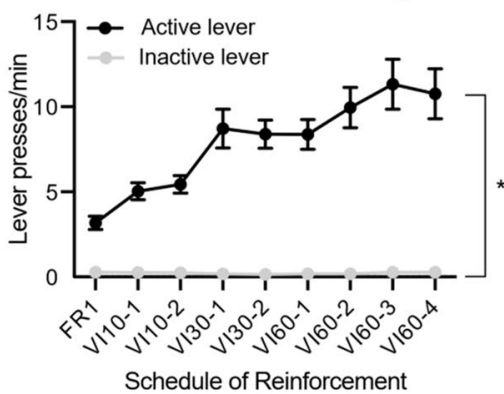

d. PIT test: Lever Pressing

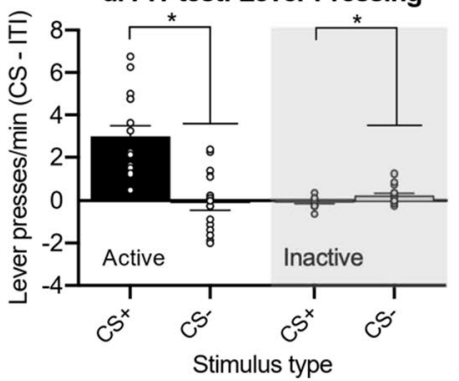

Fig. 1 After instrumental and Pavlovian conditioning, rats show significant Pavlovian-to-Instrumental transfer. (a) Timeline and behavioural schematic for Experiment 1. (b) The rate of active lever presses increased over the daily 40-min instrumental training sessions. (c) The rate of water cup entries during the first $10 \mathrm{~s}$ of each CS presentation was higher during CS + relative to CS- presentations, and this difference increased over the daily 44-min Pavlovian conditioning sessions. (d) During a test for Pavlovian-to-instrumental transfer, $\mathrm{CS}+$, but not CS- presentations invigorated lever pressing for water reward under extinction conditions. (e) During the test, rats also
Pavlovian Conditioning PIT Test

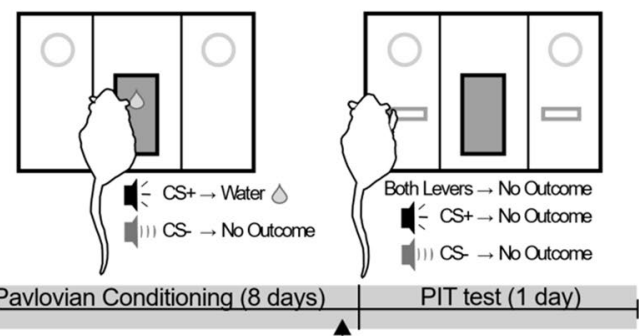

Instrumental

reminder

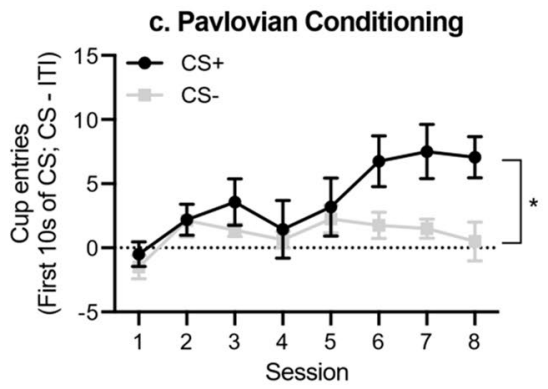

e. PIT test: Conditioned Discrimination

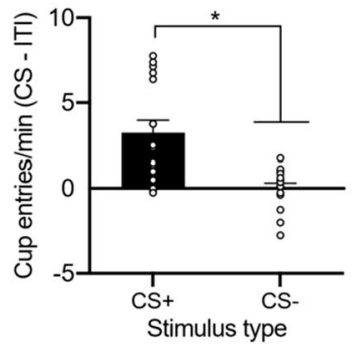

entered the water cup significantly more during $\mathrm{CS}+$ compared to CS- presentations. In (c), water cup entries are shown as a difference score between responses during the first $10 \mathrm{~s}$ of each CS presentation and during the last $10 \mathrm{~s}$ of the inter-trial interval (ITI) immediately preceding each CS presentation. In (d-e), water cup entries/lever presses are shown as a difference score between responses during the 2-min CS and during the 2-min ITI immediately preceding each CS presentation. Data are presented as means $\pm \operatorname{SEM}(\mathrm{N}=16) .{ }^{*} p<0.05$. FR; fixed ratio. VI; variable interval. CS; conditioned stimulus. 

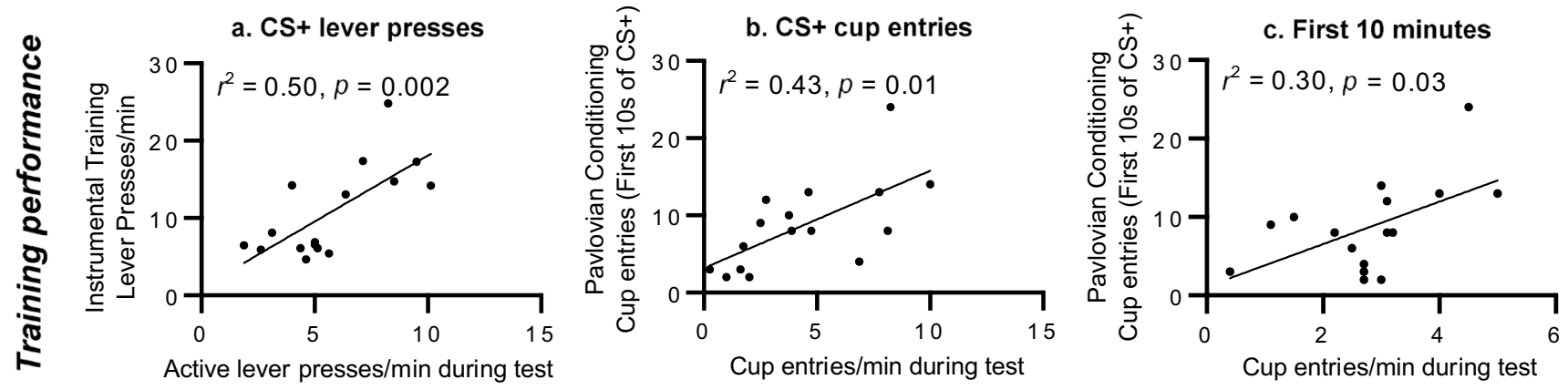

Testing performance

Fig. 2 Responding during both instrumental and Pavlovian conditioning predicted later performance during a test for Pavlovian-toinstrumental Transfer. (a) More active lever pressing during the final instrumental training session predicted more active lever pressing at test, specifically during presentations of the water-paired conditioned stimulus $(\mathrm{CS}+)$. (b) More water cup entries during $\mathrm{CS}+$ presentation on the last Pavlovian session (session 8) predicted more water cup entries at test during the $\mathrm{CS}+$. (c) More water cup entries during $\mathrm{CS}+$ presentation on the last Pavlovian session also predicted more water cup entries during the first $10 \mathrm{~min}$ of the PIT test session, when neither the $\mathrm{CS}+$ nor water were presented (i.e., under extinction conditions). $\mathrm{N}=16$. Response rates during the $\mathrm{CS}$ are unadjusted for baseline (i.e., during the inter-trial interval, or ITI). CS; conditioned stimulus.

\section{a. Timeline}
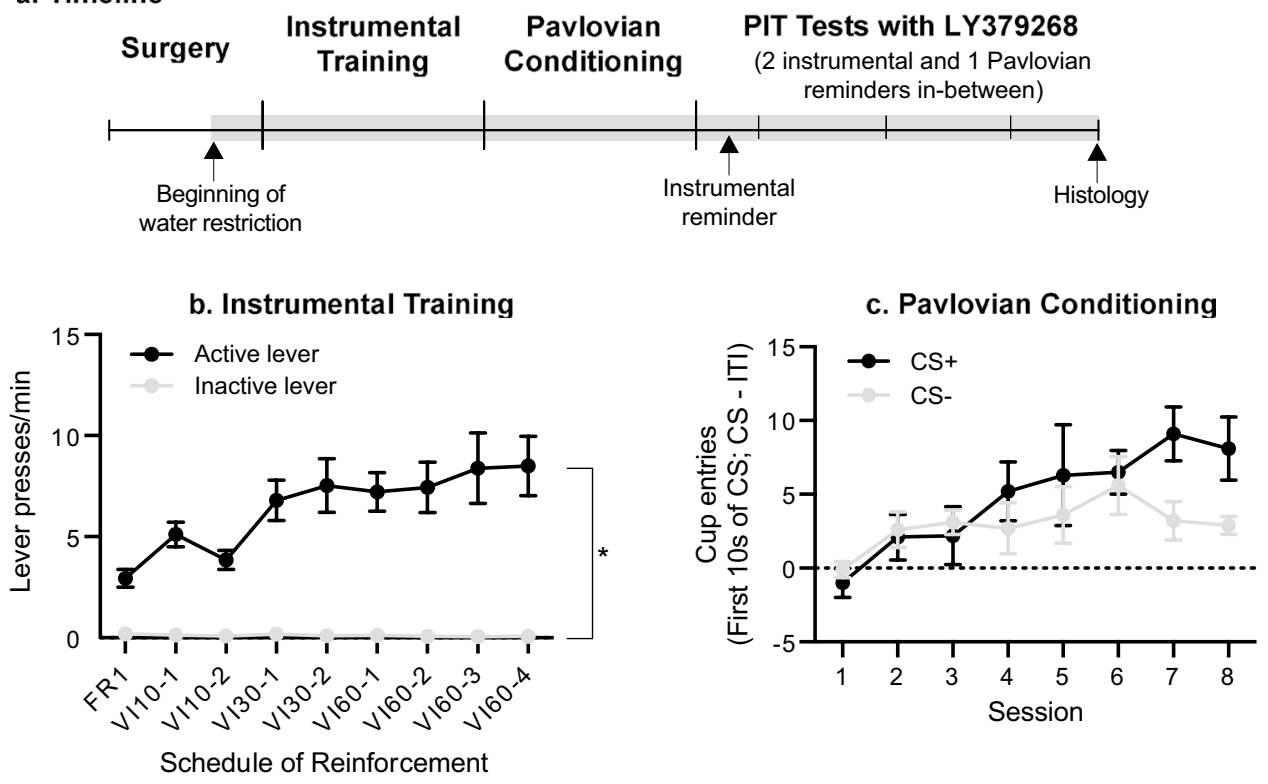

Fig. 3 ATimeline and acquisition of instrumental and Pavlovian conditioning in Experiment 2. (a) After implantation of bilateral cannulae targeting the basolateral amygdala (BLA), rats $(\mathrm{N}=10)$ received instrumental and Pavlovian conditioning sessions. We then assessed the effects of LY379268 on Pavlovian-to-instrumental transfer. (b) The rate of active-lever presses increased over the daily 40-min

instrumental training sessions. (c) The rate of water cup entries during the first $10 \mathrm{~s}$ of each CS presentation increased over the daily 44-min Pavlovian conditioning sessions. Data are presented as means \pm SEM. $* p<0.05$. FR; fixed ratio. VI; variable interval. CS; conditioned stimulus. ITI; inter-trial interval. 


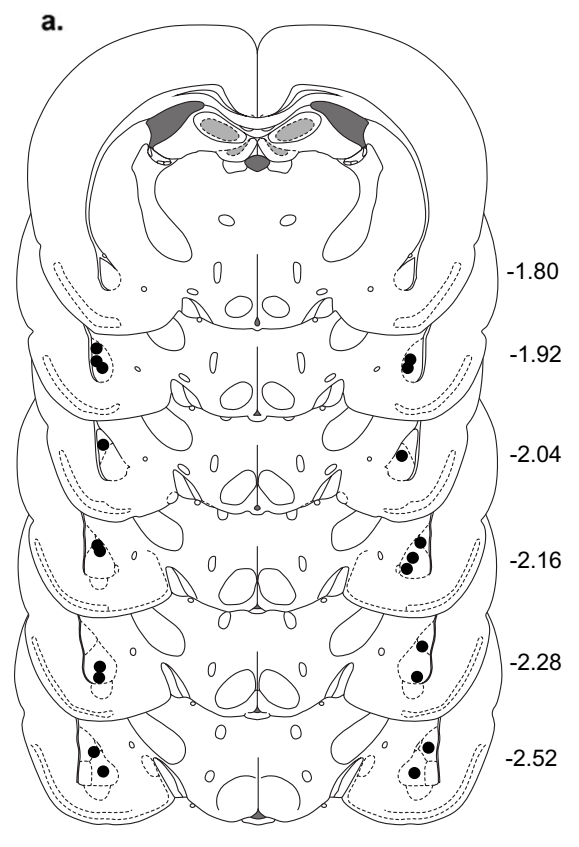

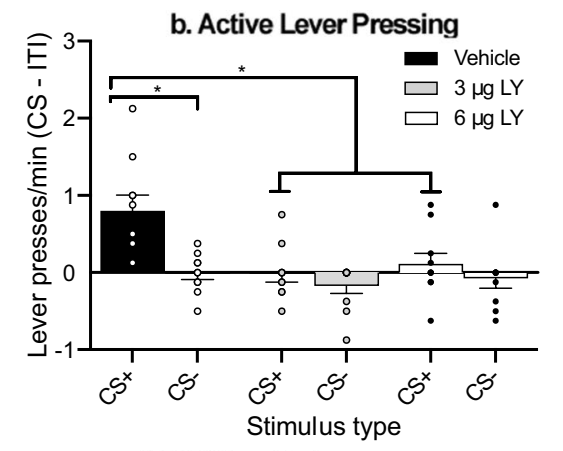

d. PIT Magnitude
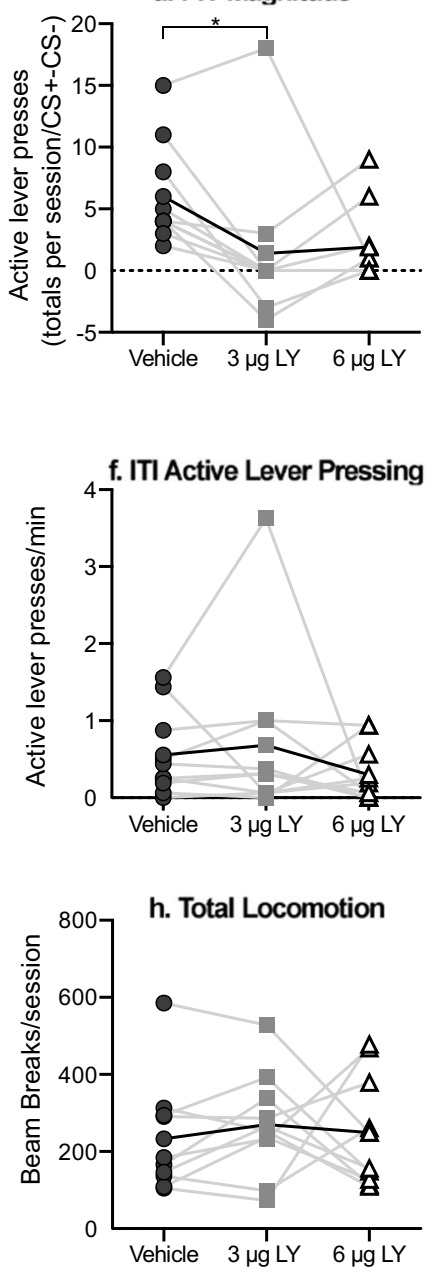

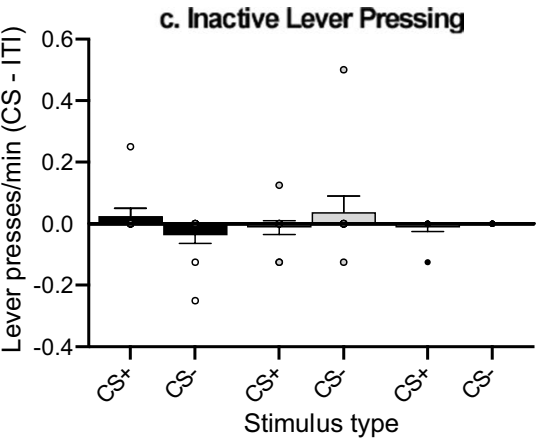

e. Conditioned Discrimination
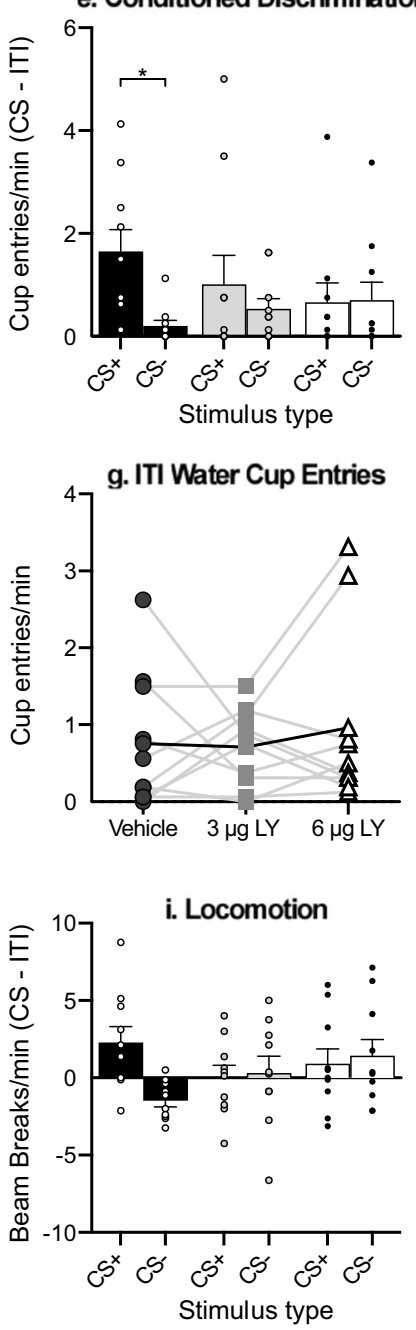

Fig. 4 Activation of basolateral amygdala (BLA) $\mathrm{mGlu}_{2 / 3}$ receptors with LY379268 abolished CS + triggered increases in both instrumental reward-seeking actions and conditioned approach behaviours. (a) Estimated placements of microinjector tips mapped to Rat brain atlas coordinates (Paxinos \& Watson, 2007). An example photomicrograph is shown below. (b) At baseline ('Vehicle'), presentation of the Pavlovian water cue $(\mathrm{CS}+)$ triggered increased responding on the water-associated lever compared to CS- presentation, and intraBLA LY379268 (3 or $6 \mu \mathrm{g} /$ hemisphere) abolished this effect. (c) LY379268 had no effect on inactive lever presses. (d) At $3 \mu \mathrm{g} / \mathrm{hemi-}$ sphere, LY379268 significantly reduced the magnitude of Pavlovian- to-instrumental transfer. (e) At baseline ('Vehicle'), rats entered the water cup significantly more often during CS + versus CS- presentations, and intra-BLA LY379268 (3 or $6 \mu \mathrm{g} /$ hemisphere) abolished this Pavlovian conditioned approach behaviour. (f-g) LY379268 had no effect on active lever presses or water cup entries during inter-trial intervals (ITI). (h) LY379268 did not influence total locomotor activity, or (i) locomotor activity during CS presentations at test. In (d), and $(\mathbf{f}-\mathbf{h})$, thicker curve in each panel represents group means. Bar graphs present data as means \pm SEM $(n=10)$. ${ }^{*} \mathrm{p}<0.05$. CS; conditioned stimulus. 